\title{
MDMA (Ecstasy) Inhibition of MAO Type A and Type B: Comparisons with Fenfluramine and Fluoxetine (Prozac)
}

\author{
Efthimia T. Kokotos Leonardi, M.S. and Efrain C. Azmitia, Ph.D.
}

3,4-Methylenedioxymethamphetamine (MDMA), a serotonin (5-HT) neurotoxin, has been shown to promote the release of serotonin (5-HT) and block its reuptake. The increased buildup of extracellular 5-HT should normally be degraded by monoamine oxidase (MAO). The effects of both enantiomers of MDMA were examined on $M A O-A$ and monoamine oxidase- $B(M A O-B)$ activity in rat brain homogenates. Both enantiomers competitively inhibited 5-HT catabolism by rat brain MAO-A. The $K_{i}$ of MDMA for MAO-A was $22 \mu \mathrm{mol} / \mathrm{L}$. A mixed type of inhibition by MDMA was observed for phenethylamine catabolism by MAO-B for both optical antipodes.

Logistical analysis of concentration response curves for $M D M A$ inhibition of $M A O-A$ and $M A O-B$ show an $I C_{50}$ of $44 \mu \mathrm{mol} / \mathrm{L}$ for inhibition of MAO-A by MDMA. The $I C_{50}$ value of MDMA inhibition of MAO-B was 370 $\mu \mathrm{mol} / \mathrm{L}$, showing a selective potency for MAO-A inhibition. The MAO inhibitory properties of fenfluramine (FEN) and fluoxetine (FLUOX) were compared to those of MDMA. The rank order potency of these drugs for MAO-A inhibition was

$M D M A>F L U O X>F E N$, whereas for $M A O-B$ inhibition, FLUOX $>M D M A>F E N$. A combination of FLUOX and $M D M A$ at their respective $I C_{50}$ did not inhibit $M A O$ activity more than either drug alone at equivalent concentrations. These results indicate that the actions of FEN do not appear to involve MAO inhibition. MDMA (ecstasy) produced a preferential inhibition of MAO-A $\left(I_{50}=44 \mu \mathrm{mol} / \mathrm{L}\right)$, which should increase extracellular 5-HT. This may explain its high toxicity potential. Finally, FLUOX (Prozac) showed an inhibition of $M A O-B\left(I C_{50}=80 \mu \mathrm{mol} / \mathrm{L}\right.$, which may increase the intracellular content of 5-HT. This may contribute to its therapeutic potential. In contrast, FEN appears to be a poor inhibitor of both MAO-A and MAO-B. [Neuropsychopharmacology 10:231-238, 1994]
KEY WORDS: Serotonin; Phenethylamine; Enantiomer

Monoamine oxidase (MAO) is an enzyme with two subtypes (E.C.1.4.3.4) characterized by their differential responses to the irreversible inhibitors clorgyline and deprenyl. Monoamine oxidase A (MAO-A) has a higher affinity for serotonin (5-HT) than MAO-B; the $K_{M}$ of MAO-A for serotonin is $99 \mu \mathrm{mol} / \mathrm{L}$, the $\mathrm{K}_{\mathrm{M}}$ of MAO-B

From the Department of Biology, New York University, New York, New York.

Address correspondence to Dr. Efrain C. Azmitia, Department of Biology, New York University, 100 Washington Square East, New York, NY 10003.

Received November 7, 1993; revised February 16, 1994; accepted February 17, 1994. for serotonin is $1170 \mu \mathrm{mol} / \mathrm{L}$ (Fowler and Tipton 1982; Garrick and Murphy 1982). Monoamine oxidase A is inhibited by nanomolar concentrations of clorgyline (Johnston 1968). Monoamine oxidase B (MAO-B) has a higher affinity for phenethylamine than MAO-A and is inhibited by nanomolar concentrations of deprenyl (Garrick and Murphy 1982; Yang and Neff 1974). Dopamine (DA) is metabolized with equal affinity by both subtypes (Yang and Neff 1974). Further evidence for two molecular forms of MAO has been provided by the cloning of two distinct MAO genes (Bach et al. 1988) and their subsequent functional expression in COS cells (Lan et al. 1989).

Both neurons and glia contain monoamine oxidases that catabolize the classical monoamine neurotransmit- 
ters. Monoamine oxidase $\mathrm{A}$ is the predominant form in catecholaminergic neurons, whereas MAO-B is the prevalent form in glia (Levitt et al. 1982; Westlund et al. 1985). Although MAO-B has a higher affinity than MAO-B for serotonin, MAO-B is the major molecular form found within serotonergic neurons (Westlund et al. 1985).

3,4-Methylenedioxymethamphetamine (MDMA) binds with high affinity to the 5-HT transporter protein (Poblete et al. 1989) and has been shown to be a potent releaser of serotonin by a $\mathrm{Ca}^{2+}$-independent mechanism (Berger et al. 1992; Gu and Azmitia 1989; Johnson et al. 1986; Schmidt 1987; Schmidt et al. 1987). MDMA has been demonstrated to produce a depletion of serotonin that may be reversed in acute stages by agents that bind to the serotonin transporter and block serotonin reuptake into presynaptic terminals (Azmitia et al. 1990; Schmidt 1987). It also inhibits the 5-HT reuptake system (Steele et al. 1987), resulting in an increased amount of extracellular 5-HT. However, little attention has been paid to the fate of extracellular 5-HT.

Parachloroamphetamine (PCA) is another substituted amphetamine that is a potent releaser of serotonin and has a biphasic depletion of serotonin similar to that observed with MDMA (Ask and Ross 1987; Berger et al. 1992; Fuller et al. 1975; Gu and Azmitia 1989; Gu 1993; Hwang and van Woert 1980; Mamounas and Molliver 1988; Poblete et al. 1989; Ross and Froden 1977). As with MDMA, the depletion of serotonin resultant from PCA may be reversed in its acute phase by serotonin uptake blockers (Fuller et al. 1975; Ross et al. 1977). Parachloroamphetamine has been shown to inhibit MAO-A activity in rat brain homogenates with a $\mathrm{K}_{\mathrm{i}}$ value of $1.31 \mu \mathrm{mol} / \mathrm{L}$ (Fuller 1966). The toxicity of PCA is also affected by the amount of releasable serotonin into the extracellular space. For instance, if serotonin release is decreased by parachlorophenylalanine (pCPA) and reserpine, the level of toxicity is reduced (Berger et al. 1989).

The anorectic compound, fenfluramine (FEN), is a halogenated amphetamine that has actions in serotonergic axon terminals similar to those of MDMA and PCA (Mamounas and Molliver 1988; Molliver and Molliver 1990; O'Hearn et al. 1988). Like MDMA and PCA, FEN causes the release of 5-HT from presynaptic terminals (Borroni et al. 1983) and inhibits the reuptake of serotonin into its terminals (Belin et al. 1976; Kannengiesser et al. 1976). The effects of FEN are blocked by 5-HT uptake inhibitors, as in MDMA and PCA (Hekmatpanah and Peroutka 1990). These observations suggest that the carrier-mediated release of serotonin and the inhibition of its reuptake are critical components in the mechanism of these drugs. FEN, FLUOX, and MDMA bind to the serotonin transporter protein with high affinity; the rank order potencies for binding to the transporter for these agents is FLUOX $>\mathrm{FEN}=$ MDMA (Poblete et al. 1989).

The similar actions of FEN, FLUOX and MDMA on serotonin transporter binding suggest they may possess common effects upon other serotonergic parameters, such as monoamine oxidase activity, in vitro. The present report examines the effects of both enantiomers of MDMA on catabolism of $\left[{ }^{3} \mathrm{H}\right]$-serotonin and $\left[{ }^{14} \mathrm{C}\right]$ phenethylamine by rat brain monoamine oxidase in vitro. In addition, we compared the effects of fluoxetine (FLUOX) and fenfluramine (FEN) to MDMA on rat brain MAO activity. Our results suggest that inhibition of MAO-A by MDMA may contribute to an accumulation of extracellular 5-HT. The inhibition of MAO-B activity by FLUOX may increase intracellular 5-HT, whereas the actions of FEN do not appear to involve MAO inhibition.

\section{MATERIALS AND METHODS}

Male Sprague-Dawley rats weighing 200 to $250 \mathrm{~g}$ (Taconic Farms, Germantown, NY) were housed two per cage and given free access to food and water. The animals were maintained on a 12-hour light/dark cycle. Animals were euthanized with $\mathrm{CO}_{2}$ and decapitated according to a protocol approved by the NYU Animal Welfare Committee. Brains were rapidly removed and placed on ice in $0.32 \mathrm{~mol} / \mathrm{L}$ sucrose. After removal of the cerebellum, brains were homogenized in 10 -fold volume/weight in $0.32 \mathrm{~mol} / \mathrm{L}$ sucrose using 10 strokes with a Teflon/glass homogenizer. $P_{1}$ pellets were prepared by sedimentation of homogenates at $800 \times \mathrm{g}$ for 10 minutes at $2^{\circ} \mathrm{C}$ in a Sorvall RC5C centrifuge (Sorvall Instruments, DuPont, Chadds Ford, PA). Supernatants were resedimented at $14,000 \times g$ at $2^{\circ} \mathrm{C}$ for 15 minutes to obtain a crude mitochondrial $\mathrm{P}_{2}$ pellet. Resultant pellets were resuspended in $500 \mu \mathrm{L} 0.32 \mathrm{~mol} / \mathrm{L}$ sucrose and stored at $-70^{\circ} \mathrm{C}$ until use.

Prior to the MAO assay, homogenates were thawed and brought up to $10 \times$ volume/original weight 0.01 $\mathrm{mol} / \mathrm{L}$ sodium phosphate buffer (PB), $\mathrm{pH} 7.4$ and dialyzed to remove endogenous monoamines by a modification of the method described by Patterson, et al. (1973). Briefly, homogenates were dialyzed in $2 \mathrm{~mL}$ aliquots using $3500 \mathrm{mw}$ cutoff dialysis tubing (Spectrapor) against $0.01 \mathrm{~mol} / \mathrm{L} \mathrm{PB}, \mathrm{pH} 7.4$ at $4^{\circ} \mathrm{C}$ for 2 hours with three successive changes of $1 \mathrm{~L}$ buffer. MAO assays were performed immediately following this dialysis.

Monamine oxidase activity was assayed using $\left[{ }^{3} \mathrm{H}\right]-5-\mathrm{HT}(25 \mathrm{Ci} / \mathrm{mmol}, 1 \mu \mathrm{Ci} / \mathrm{mL}$, New England Nuclear, Boston, MA) as a substrate for MAO-A at final concentrations ranging from $12.5 \mu \mathrm{mol} / \mathrm{L}$ to $400 \mu \mathrm{mol} / \mathrm{L}$. $\left[{ }^{14} \mathrm{C}\right]$-phenethylamine at a final concentration of 5 


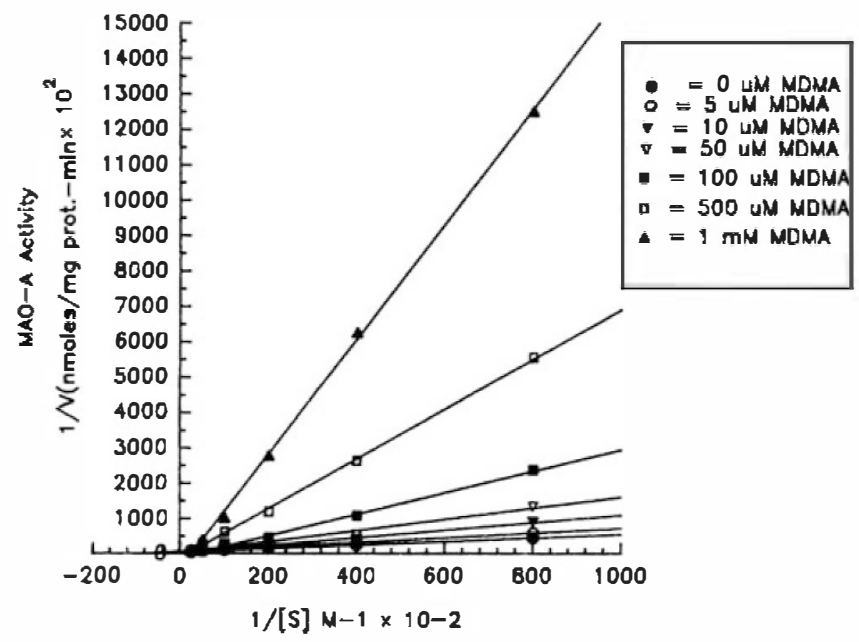

Figure 1. Inhibition of serotonin oxidation by (+) MDMA. All data points represent the average of three experiments. Nonspecific values $(0.15 \mathrm{nmoles}$ product $/ \mathrm{mg}$ protein-minute) were subtracted from total activity. Error bars represent the standard error of the mean.

$\mu \mathrm{mol} / \mathrm{L}$ to $50 \mu \mathrm{mol} / \mathrm{L}(50.8 \mathrm{mCi} / \mathrm{mmol}, 0.1 \mu \mathrm{Ci} / \mathrm{mL}$, New England Nuclear, Boston, MA) served as substrate for MAO-B. The assay procedure was a modification of the method described by Pintar et al. (1981) and Lan et al. (1989).

\section{Competition Studies}

A $15 \mu \mathrm{L}$ portion of rat brain homogenate suspended in $75 \mu \mathrm{L} 0.01 \mathrm{~mol} / \mathrm{L} \mathrm{PB}$ was treated with $20 \mu \mathrm{L}(+)$ or (-) MDMA (National Institute on Drug Abuse, Bethesda, MD) at final concentrations ranging from 10 $\mu \mathrm{mol} / \mathrm{L}$ to $1 \mathrm{mmol} / \mathrm{L}, 10$ minutes in a $37^{\circ} \mathrm{C}$ water bath. Samples then received a $90 \mu \mathrm{L}$ aliquot of $\left[{ }^{14} \mathrm{C}\right]-\mathrm{PEA}$ or $\left[{ }^{3} \mathrm{H}\right]-5-\mathrm{HT}$ and were further incubated in a $37^{\circ} \mathrm{C}$ water bath for 30 minutes. At the end of this time, the reaction was terminated by adding a $90 \mu \mathrm{L}$ aliquot $1.2 \mathrm{~mol} / \mathrm{L}$ $\mathrm{HCl}$. Each sample point was assayed in quadruplicate. Radioactive product was measured by the addition of $3 \mathrm{~mL} \mathrm{4 \%} \mathrm{(vol/vol)} \mathrm{Liquiscint} \mathrm{(National} \mathrm{Diagnostics,}$ Bethesda, MD):toluene (HPLC grade, Aldrich Chemical Co., Milwaukee, WI) per sample followed by scin- tillation counting in Beckman LS 1801 scintillation counter (Fullerton, CA) with a counting efficiency of $40 \%$.

\section{Comparison of FEN, FLUOX, and MDMA}

Fenfluramine, FLUOX, and each enantiomer of MDMA were assayed against MAO-A and MAO-B activity with substrate concentrations of $100 \mu \mathrm{mol} / \mathrm{L} 5-\mathrm{HT}$ and 20 $\mu \mathrm{mol} / \mathrm{L}$ PEA, respectively. Fenfluramine (Sigma Chemical Co., St. Louis, MO) and MDMA were tested at final concentrations of $1 \mu \mathrm{mol} / \mathrm{L}$ to $10 \mathrm{mmol} / \mathrm{L}$, FLUOX (gift of Eli Lilly and Co., Indianapolis, IN) at concentrations of $1 \mu \mathrm{mol} / \mathrm{L}$ to $1 \mathrm{mmol} / \mathrm{L}$. MAO activity was then assayed as described above.

\section{Additive Effects}

To determine whether MDMA and FLUOX share a common mechanism for MAO inhibition, homogenates were treated with FLUOX and (+) MDMA in combination at their $\mathrm{IC}_{50}$ or at $2 \times \mathrm{IC}_{50}$ concentrations individually. Radiolabeled substrate was added and MAO activity was assayed as described above.

To determine nonspecific counts, a set of samples was preincubated with $1 \mathrm{mmol} / \mathrm{L}$ clorgyline or $1 \mathrm{mmol} / \mathrm{L}$ deprenyl, as appropriate, for 10 minutes at $37^{\circ} \mathrm{C}$. Protein concentrations of homogenates were determined by the method of Lowry et al. (1951) with bovine serum albumin (Sigma Chemical Co., St. Louis, MO) as standard. Protein detection was determined at $540 \mathrm{~nm}$ absorbance using a Titertek Multiskan spectrophotometer (EFLAB, Helsinki, Finland).

Analysis of data was conducted by employing Student's two-tailed $t$-test for two-sample comparisons. One-way analysis of variance (ANOVA) followed by Tukey post hoc analysis was performed for multisample comparisons (SYSTAT, Evanston, IL). IC 50 values and Hill coefficients of concentration-response curves were determined by computer-assisted curve-fitting to a logistical equation (SigmaPlot 4.1, Jandel Scientific, San Rafael, CA). Kinetic constants for both subtypes of MAO were determined by the analysis of LineweaverBurk plots.

Table 1. Comparison of $(+)$ and (-) MDMA against Deamination of Serotonin and PEA by MAO

\begin{tabular}{lcccc}
\hline $\begin{array}{l}\text { Substrate of } \\
\text { MAO }\end{array}$ & $\begin{array}{c}\mathbf{V}_{\text {max }} \\
\text { (nmol/mg-minute) }\end{array}$ & $\begin{array}{c}\mathbf{K}_{\mathrm{M}} \\
(\mu \mathrm{mol} / \mathrm{L})\end{array}$ & $\begin{array}{c}\mathbf{K}_{\mathbf{i}}(+) \text { MDMA } \\
(\mu \mathbf{m o l} / \mathbf{L})\end{array}$ & $\begin{array}{c}\mathbf{K}_{\mathbf{i}}(-) \mathbf{M D M A} \\
(\mu \mathbf{m o l} / \mathbf{L})\end{array}$ \\
\hline Serotonin & $2.08 \pm 0.03$ & $100 \pm 12$ & $22.0 \pm 3^{*}$ & $28.3 \pm 5.0^{*}$ \\
PEA & $1.72 \pm 0.20$ & $20 \pm 3$ & - & - \\
\hline
\end{tabular}

\footnotetext{
* No significance was determined between $(+)$ and $(-)$ MDMA with Student's two-tailed $t$-test. Values reported here represent the average of three experiments, plus or minus the standard error of the mean.
} 


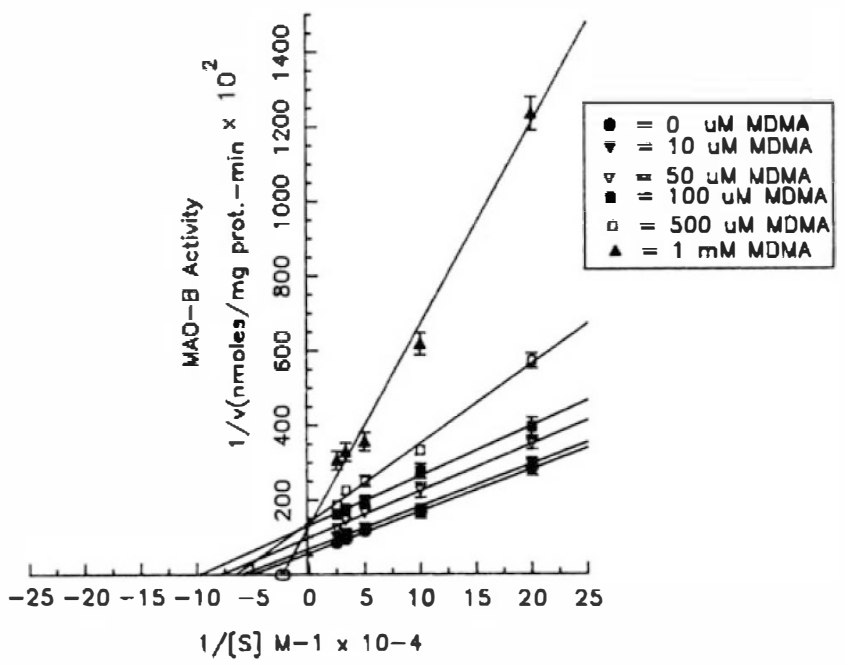

Figure 2. Inhibition of phenethylamine oxidation by $(+)$ MDMA. All data points represent the average of three experiments. Nonspecific values $(0.18 \mathrm{nmoles}$ product $/ \mathrm{mg}$ protein-minute) were subtracted from total activity. Error bars represent the standard error of the mean.

\section{RESULTS}

In order to establish the kinetic parameters of MAO activity in this assay system, saturation studies were performed for MAO-A and MAO-B. MAO-A activity had a $V_{\max }$ of $2.08 \mathrm{nmoles}$ product $/ \mathrm{mg}$ protein-minute and a $\mathrm{K}_{\mathrm{M}}$ of $100 \mu \mathrm{mol} / \mathrm{L}$ (Figure 1, Table 1). For MAO-B, a $\mathrm{V}_{\max }$ of 1.72 nmoles product/mg protein-minute with a $\mathrm{K}_{\mathrm{M}}$ value of $20 \mu \mathrm{mol} / \mathrm{L}$ was observed (Figure 2, Table 1). Both enzyme assay systems were responsive to the appropriate monoamine oxidase inhibitors; clorgyline with a $\mathrm{K}_{\mathrm{i}}$ for MAO-A of $0.5 \mathrm{nmol} / \mathrm{L}$ and deprenyl with a $\mathrm{K}_{\mathrm{i}}$ for MAO-B of $1 \mathrm{nmol} / \mathrm{L}$.

Once these parameters were established, the effects of both enantiomers of MDMA were tested on MAO-A. A different $K_{M}$ but no change in $V_{\max }$ was observed for MAO-A (Figure 1) with increasing concentrations of MDMA, indicative of a competitive inhibition. No stereospecific effect was observed (Table 1$)$, that is $(+)$ MDMA had a $K_{i}$ value of $22.0 \mu \mathrm{mol} / \mathrm{L}$ against serotonin as substrate and (-) MDMA has a $K_{i}$ value of 28.3 $\mu \mathrm{mol} / \mathrm{L}$ (Table 1). A competitive inhibition of MAO-A was seen by both enantiomers of MDMA.

The effects of both enantiomers of MDMA were determined for MAO-B, the subtype of MAO localized within serotonergic neurons. MDMA produced a different type of inhibition with MAO-B than was observed for MAO-A (Figures 1, 2). In the case of MAO-B, both the $V_{\max }$ and $K_{M}$ of the enzyme were changed by a range of MDMA concentrations; 10, 50, 100, and 500 $\mu \mathrm{mol} / \mathrm{L}$. At the highest concentrations, $1 \mathrm{mmol} / \mathrm{L}$, the $V_{\max }$ remained the same whereas $K_{M}$ has changed. The change in both the $V_{\max }$ and $K_{M}$ shows a mixed-type

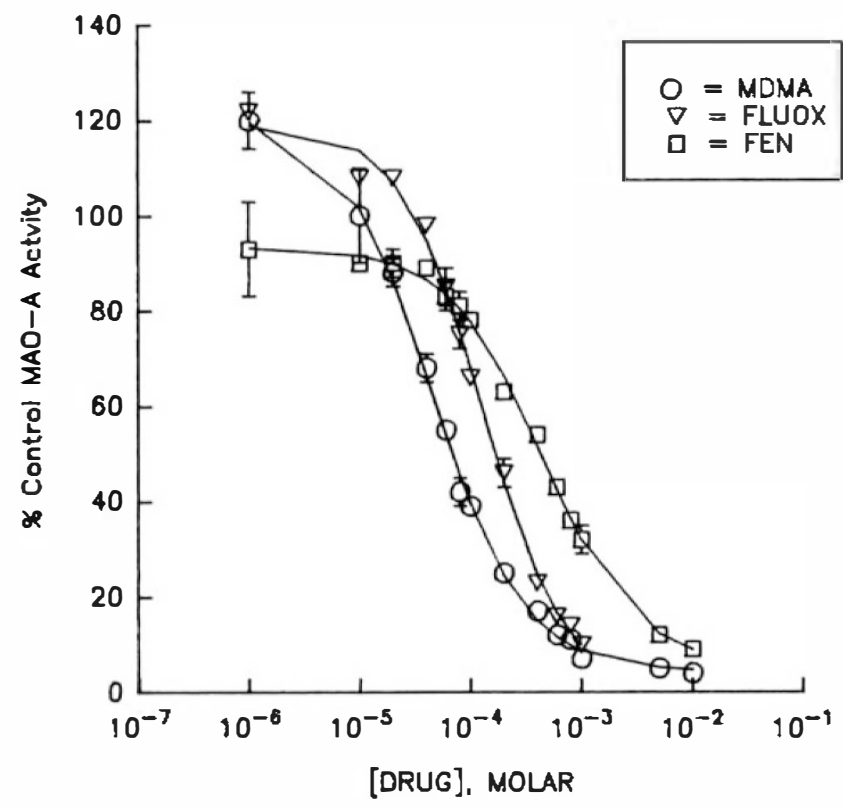

Figure 3. Concentration-response curve for the inhibition of MAO-A by FLUOX, FEN, and (+) MDMA. Control values = $2.08 \mathrm{nmoles}$ product/mg protein-minute. Error bars represent the standard error of the mean.

inhibition of MAO-B by MDMA; the effect observed at the highest concentrations may reflect a saturation of all the available MAO-B active sites. A similar finding was observed with (-) MDMA (data not shown).

To compare the potencies of FEN, FLUOX, and MDMA on MAO-A inhibition, concentration-response curves were established that consisted of 14 points from $10^{-6}$ to $10^{-2} \mathrm{~mol} / \mathrm{L}$ for MDMA and FEN. A concentration-response curve of 13 points from $10^{-6}$ to $10^{-3}$ $\mathrm{mol} / \mathrm{L}$ was established for FLUOX. A representative curve obtained from the average of three experiments for FEN, FLUOX, and (+) MDMA had Hill coefficients of $1.02,1.18$, and 1.05, respectively (Figure 3 ). Their respective $\mathrm{IC}_{50}$ values (Table 2 ) show a rank order potency of MDMA $>$ FLUOX $>$ FEN $\left(\mathrm{IC}_{50}\right.$ were 44,130 , and $440 \mu \mathrm{mol} / \mathrm{L}$, respectively). The $\mathrm{IC}_{50}$ of (-) MDMA for MAO-A was $56 \mu \mathrm{mol} / \mathrm{L}$ (Table 2).

A similar study was performed for MAO-B with the drugs at the same concentrations as the MAO-A experiment. A representative curve obtained from the average of three experiments for FEN, FLUOX, and (+) MDMA had Hill coefficients of $1.13,1.12$, and 0.8182 , respectively (Figure 4). Table 2 shows their respective $\mathrm{IC}_{50}$ values; 720,80 , and $370 \mu \mathrm{mol} / \mathrm{L}$ with FLUOX> MDMA $>$ FEN. As was the case with MAO-A, no significant difference in $\mathrm{IC}_{50}$ was observed between $(+)$ and (-) MDMA for MAO-B activity. The $\mathrm{IC}_{50}$ of (+) MDMA for MAO-B inhibition was roughly nine times greater than its $\mathrm{IC}_{50}$ for $\mathrm{MAO}-\mathrm{A}$, indicating that MDMA is selectively potent for MAO-A activity. 
Table 2. $\mathrm{IC}_{50}$ Values $(\mu \mathrm{mol} / \mathrm{L}) \pm \mathrm{SEM}$

\begin{tabular}{lcccr}
\hline MAO Subtype & FEN & FLUOX & (+) MDMA & ( $)$ ) MDMA \\
\hline MAO-A & $440 \pm 23.09^{a b}$ & $130 \pm 11.55^{a}$ & $44 \pm 6.06$ & $56 \pm 8.24$ \\
MAO-B & $720 \pm 28.87^{a b}$ & $80 \pm 10.55^{a}$ & $370 \pm 4.68^{a b}$ & $378 \pm 6.29$
\end{tabular}

Values represent the average of three experiments \pm standard error of the mean. MAO-A Data: One-way analysis of variance showed significant variance $\left(p=1.02 \times 10^{-7}, F=183.86, F_{\text {crit }}=4.07\right)$. MAO-B Data: One-way analysis of variance showed significant variance $\left(p=6.16 \times 10^{-8}, F=209.05\right.$, $F_{\text {crit }}=4.07$ ).

${ }_{b}^{a} p<.001$ when compared to (+) MDMA with Tukey post hoc analysis.

${ }^{b} p<.001$ when compared to FLUOX with Tukey post hoc analysis.

FLUOX showed a $60 \%$ greater inhibition of MAO-B than MAO-A activity, with an $\mathrm{IC}_{50}$ of $80 \mu \mathrm{mol} / \mathrm{L}$ for MAO-B. FEN showed poor inhibition of both MAO-A and MAO-B.

The additive effects of MDMA and FLUOX were tested. In this set of experiments, each drug was added to homogenates at its $\mathrm{IC}_{50}$ or $2 \times \mathrm{IC}_{50}$. Another group had homogenates receiving a combination of both drugs at their respective $\mathrm{IC}_{50}$ values. In this way, we were able to test whether MDMA and FLUOX share a common mechanism for MAO-A and - B inhibition. A combination of FLUOX and MDMA at their $\mathrm{IC}_{50}$ did not inhibit MAO-A or MAO-B activity more than either drug alone at an equivalent concentration, which is indicative of a common mechanism for MAO inhibition (Table 3, Table 4).

\section{DISCUSSION}

Amphetamine has been reported as a competitive inhibitor of MAO-A activity (Mantle et al. 1976) and a mixed inhibitor of MAO-B, that is, both the $\mathrm{V}_{\max }$ and $K_{M}$ are changed (Pearce and Roth 1985). The results of this study show MDMA acts as a competitive inhibitor of MAO-A activity (see Results, Figure 1), whereas a mixed pattern of inhibition was observed for the MDMA inhibition of MAO-B (Figure 2). The kinetics of MAO-A and - $B$ inhibition by MDMA reported here are therefore consistent with those previously described for amphetamine. A nine-fold difference was observed in the IC 50 of MDMA for MAO-A and MAO-B activity, showing a selective potency of MDMA for MAO-A in rat brain homogenates (see Results, Figures 3 and 4, Table 2). This finding is consistent with studies showing the

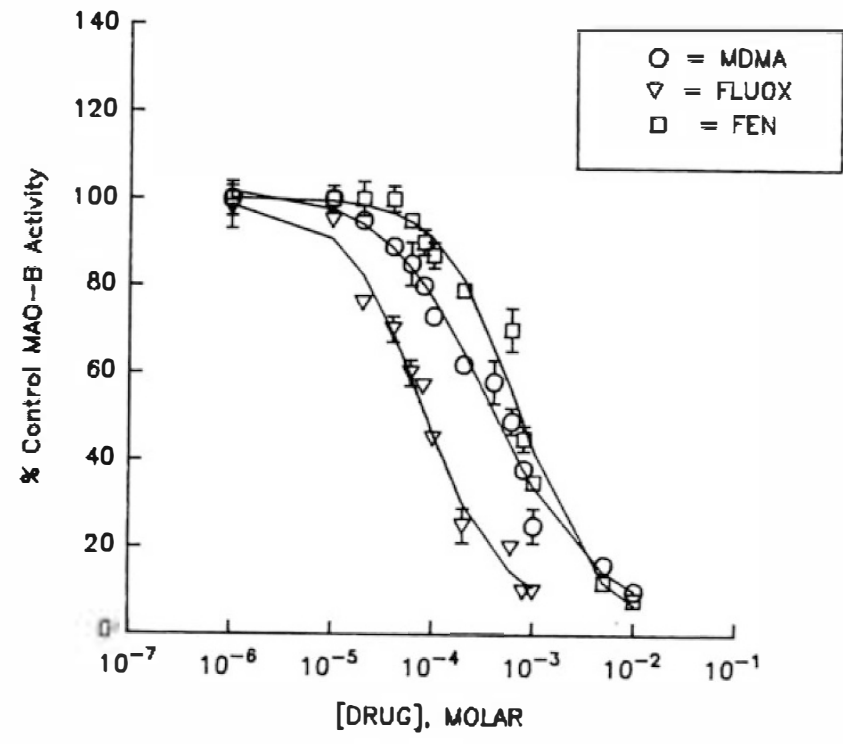

Figure 4. Concentration-response curve for the inhibition of MAO-B by FLUOX, FEN, and (+) MDMA. Control values = $1.74 \mathrm{nmoles}$ product/mg protein-minute. Error bars represent the standard error of the mean.

in vitro inhibition of MAO-A by amphetamine (Mantle et al. 1976) and its analogue, PCA (Fuller et al. 1965). A selective potency for the inhibition of the A subtype was also observed in vivo in rat brain homogenates 25 hours after the animals were injected with amphetamine followed by phenelzine, a nonselective MAO inhibitor (Miller et al. 1980).

The inhibition of MAO-A by amphetamine was found to be stereoselective for the $(+)$ enantiomer in previous studies by other investigators (Mantle et al.

Table 3. Combined Effects of (+) MDMA and Fluoxetine on MAO-A Activity

\begin{tabular}{|c|c|c|c|c|c|}
\hline & $\begin{array}{c}\text { MDMA } \\
(44 \mu \mathrm{mol} / \mathrm{L})\end{array}$ & $\begin{array}{c}\text { FLUOX } \\
(130 \mu \mathrm{mol} / \mathrm{L})\end{array}$ & $\begin{array}{c}\text { MDMA } \\
(88 \mu \mathrm{mol} / \mathrm{L})\end{array}$ & $\begin{array}{c}\text { FLUOX } \\
(260 \mu \mathrm{mol} / \mathrm{L})\end{array}$ & $\begin{array}{c}\text { MDMA } \\
(44 \mu \mathrm{mol} / \mathrm{L}) \\
+ \text { FLUOX } \\
(130 \mu \mathrm{mol} / \mathrm{L})\end{array}$ \\
\hline$\%$ Control MAO-A & $49 \pm 5$ & $50 \pm 4$ & $28 \pm 3$ & $34 \pm 5$ & $30 \pm 2$ \\
\hline
\end{tabular}


Table 4. Combined Effects of (+) MDMA and Fluoxetine on MAO-B Activity

\begin{tabular}{|c|c|c|c|c|c|}
\hline & $\begin{array}{c}\text { MDMA } \\
(370 \mu \mathrm{mol} / \mathrm{L})\end{array}$ & $\begin{array}{c}\text { FLUOX } \\
(80 \mu \mathrm{mol} / \mathrm{L})\end{array}$ & $\begin{array}{c}\text { MDMA } \\
(740 \mu \mathrm{mol} / \mathrm{L})\end{array}$ & $\begin{array}{c}\text { FLUOX } \\
(160 \mu \mathrm{mol} / \mathrm{L})\end{array}$ & $\begin{array}{c}\text { MDMA } \\
(370 \mu \mathrm{mol} / \mathrm{L}) \\
+ \text { FLUOX } \\
(80 \mu \mathrm{mol} / \mathrm{L})\end{array}$ \\
\hline$\%$ Control MAO-B & $55 \pm 4$ & $50 \pm 3$ & $35 \pm 3$ & $29 \pm 3$ & $31 \pm 2$ \\
\hline
\end{tabular}

1976). We observed no significant difference between both enantiomers of MDMA with respect to oxidative deamination of serotonin and phenethylamine by monoamine oxidase (see Results, Table 1). This is in contrast to reports of a stereospecificity for MDMA on dopamine and serotonin release from striatum (Johnson et al. 1986; Schmidt et al. 1987). However, the observation that MDMA appears to lack stereospecificity for MAO inhibition is consistent with many of the acute properties of this drug both in vivo and in vitro. Release of serotonin observed in ${ }^{3} \mathrm{H}$-serotonin-loaded rat hippocampal slices superfused with either enantiomer of MDMA did not show any significant stereoselectivity (Johnson et al. 1986). Treatment with both enantiomers of MDMA resulted in a decrease in rat striatal indoles in vivo 3 hours after injection. A nonstereoselective, acute depletion of serotonin following MDMA treatment in vivo was observed in rat cortex (Schmidt 1987). Finally, both the optical antipodes of MDMA were potent inhibitors of ${ }^{3} \mathrm{H}$-serotonin uptake into rat hippocampal synaptosomes (Steele et al. 1987). The ability of MDMA to inhibit MAO-A would result in high extracellular levels of 5-HT.

Monoamine oxidase $\mathrm{A}$ is an enzyme whose preferred substrate is serotonin (Garrick and Murphy 1982) and is localized in dopaminergic neurons (Westlund et al. 1985). Serotonin has recently been reported to promote the release of DA through the dopamine transporter by an exchange-diffusion mechanism (Jacocks and Cox 1992). This effect would be enhanced by an increased level of 5-HT resultant from an inhibition of MAO-A activity.

Fenfluramine and MDMA share many neuropharmacologic characteristics. Both drugs bind to the serotonin transporter, with a similar affinity (Poblete et al. 1989). MDMA and FEN both release serotonin (E.C.50 $=2.92$ and $7.90 \mu \mathrm{mol} / \mathrm{L}$, respectively, Berger et al. 1992; Borroni et al. 1983; Buczko et al. 1975; Johnson et al. 1986; Kannengiesser et al. 1976; Schmidt et al. 1987), with FEN being more potent. In contrast, MDMA appears to be slightly more potent than FEN at inhibition of reuptake $(0.42 \mu \mathrm{mol} / \mathrm{L}$, Steele et al. 1987 and 0.876 $\mu \mathrm{mol} / \mathrm{L}$, Borroni et al. 1983, respectively). Finally, both drugs are toxic to serotonergic neurons (Appel et al. 1990; Azmitia et al. 1990; Battaglia et al. 1987, 1988; Molliver and Molliver 1990; O'Hearn et al. 1988), but MDMA has been shown to be a more potent toxic agent than FEN in both tissue culture experiments ( $\mathrm{Gu} 1993)$ and in vivo (Sotelo and Zamora 1978). The fact that MDMA has greater toxicity is not due to its ability to induce release or bind to the serotonin transporter. However, a comparison between MDMA and FEN on MAO activity in this study showed MDMA to be approximately ten times more potent than FEN in the inhibition of MAO-A (see Results, Table 2). The inhibition of MAO-A may be a crucial variable for induced fiber degeneration. In support of this hypothesis, PCA, which is a more potent serotonergic toxin than MDMA (Gu 1993; Mamounas and Molliver 1988; O'Hearn et al. 1988) has a roughly 20-fold higher affinity for MAOA than MDMA ( $\mathrm{K}_{\mathrm{i}}$ values of $1.33 \mu \mathrm{mol} / \mathrm{L}$, Fuller 1966 vs. $22 \mu \mathrm{mol} / \mathrm{L}$, this study).

Fluoxetine is a lipophilic, serotonin uptake blocker that is found in subcellular fragments prepared from brain tissue of FLUOX-treated rats (Caccia et al. 1990). Therefore, FLUOX may enter the cell and interact with monoamine oxidase. The $\mathrm{IC}_{50}$ of FLUOX was compared to that of MDMA and FEN with respect to MAO inhibition; the $\mathrm{IC}_{50}$ value of FLUOX for MAO-A was nearly three times higher than that of MDMA (see Results, Table 2). Interestingly, the $\mathrm{IC}_{50}$ of FLUOX for MAO-B, the subtype localized within serotonergic cells, was $80 \mu \mathrm{mol} / \mathrm{L}$, a nine-fold difference from the $\mathrm{IC}_{50}$ of MDMA.

Finally, the additive properties of FLUOX and MDMA were tested on MAO activity (Results, Table 3 , Table 4). Since both compounds bind to the serotonin transporter, we examined whether they share a common site for MAO inhibition. The addition of both drugs at their $\mathrm{IC}_{50} \mathrm{~s}$ produced effects that were equivalent to each drug on its own. We interpret this finding to be indicative of a competition of both compounds for the same site on MAO-A and MAO-B, respectively (Results, Table 3, Table 4).

In summary, these studies show that MDMA preferentially inhibits MAO-A in a reversible, nonstereospecific manner. Fluoxetine is significantly more potent than MDMA in the inhibition of MAO-B, whereas FEN does not significantly affect rat brain MAO-A or MAO$B$ activity. Like PCA, the greater toxicity of MDMA (Gu 1993) may be related to its ability to produce high levels of extracellular 5-HT by stimulating release, inhibiting reuptake and blocking the catabolism of serotonin by MAO-A. The therapeutic actions of Prozac may in- 
volve a selective inhibition of MAO-B, which would result in a greater amount of 5-HT available for release. Finally, FEN has only weak effects on MAO-A and MAO-B activity.

\section{ACKNOWLEDGMENTS}

The comments made by H. Kenneth Kramer, Dr. Randall B. Murphy, and Jose C. P. Poblete during the preparation of the manuscript are gratefully acknowledged. This work was supported by NIDA contract \#271-90-7403.

\section{REFERENCES}

Appel NM, Mitchell WM, Contrera JF, DeSouza EB (1990): Effects of High Dose Fenfluramine Treatment on Monoamine Uptake Sites in Rat Brain: Assessment Using Quantitative Autoradiography. Synapse 6:33-44

Ask A-L, Ross SB (1987): Inhibition of 5-Hydroxytryptamine Accumulation and Deamination by Substituted Phenylalkylamines in Hypothalamic Synaptosomes from Normal and Reserpine-Treated Rats. Arch Pharmacol 336:591-596

Azmitia EC, Murphy RB, Whitaker-Azmitia PM (1990): MDMA (Ecstasy) Effects on Cultured Serotonergic Neurons: Evidence for $\mathrm{Ca}^{+2}$-dependent Toxicity Linked to Release. Brain Res 510:97-103

Bach AWJ, Lan NC, Johnson DH, Abell CW, Bembenek ME, Kwan S-W, Seeburg PH, Shih JC (1988): cDNA Cloning of Human Liver Monoamine Oxidase A and B: Molecular Basis of Differences in Enzymatic Properties. Proc Natl Acad Sci USA 85:4934-4938

Battaglia G, Yeh SY, O'Hearn E, Molliver ME, Kuhar MJ, DeSouza EB (1987): 3,4-Methylenedioxymethamphetamine and 3,4-Methylenedioxyamphetamine Destroy Serotonin Terminals in Rat Brain. Quantification of Neurodegeneration by Measurement of $\left[{ }^{3} \mathrm{H}\right]$-ParoxetineLabelled Serotonin Uptake Sites. J Pharmacol Exp Ther 242:911-916

Battaglia G, Yeh SY, DeSouza EB (1988): MDMA-Induced Neurotoxicity: Parameters of Degeneration and Recovery of Brain Serotonin Neurons. Pharmacol Biochem Behav 29(2):269-273

Belin M-F, Kouyoumdjian J-C, Bardakdjian J, Duhault J, Gonnard P (1976): Effects of Fenfluramine in Accumulation of Serotonin and Other Neurotransmitters into Synaptosomes of Rat Brain. Neuropharmacology 15:613-617

Berger UV, Grzanna R, Molliver ME (1989): Depletion of serotonin using p-Chlorophenylalanine (PCPA) and Reserpine Protects Against the Neurotoxic Effects of p-Chloroamphetamine (PCA) in the Brain. Exp Neurol 103:111-115

Berger UV, Gu XF, Azmitia EC (1992): The Substituted Amphetamines 3,4-Methylenedioxymethamphetamine, p-Chloroamphetamine and Fenfluramine Induce 5-HT Release Via a Common Mechanism Blocked by Fluoxetine and Cocaine. Eur J Pharmacol 215:153-160

Borroni E, Ceci A, Garattini S, Mennini T (1983): Differences Between d-Fenfluramine and d-Norfenfluramine in Serotonin Presynaptic Mechanisms. J Neurochem 40:891-893
Buczko W, DeGaetano G, Garattini S (1975): Effect of Fenfluramine on 5-Hydroxytryptamine Uptake and Release by Rat Blood Platelets. Brit J Pharmacol 53:563-568

Caccia S, Cappi M, Fracasso C, Garattini S (1990): Influence of Dose and Route of Administration of Fluoxetine and its Metabolite Norfluoxetine in the Rat. Psychopharmacology 100:509-514

Fowler CJ, Tipton KF (1982): Deamination of Serotonin by Both Forms of Monoamine Oxidase in the Rat Brain. J Neurochem 38:733-736

Fuller RW (1966): Serotonin Oxidation by Rat Monoamine Oxidase: Inhibition by 4 -Chloroamphetamine. Life Sci $5: 2247-2252$

Fuller RW, Hines CW, Mills J (1965): Lowering of Brain Serotonin by Chloramphetamines. Biochem Pharmacol 14:483-488

Fuller RW, Perry KW, Molloy BB (1975): Reversible and Irreversible Phases of Serotonin Depletion by 4 -Chloroamphetamine. Eur J Pharmacol 33:119-124

Garrick NA, Murphy DL (1982): Monoamine Oxidase Type A: Differences in Selectivity Towards I-Norepinephrine Compared to Serotonin. Biochem Pharmacol 31:40614066

Gu XF (1993): Integrative Release of 5-HT from Cultured Raphe Neurons. Doctoral Dissertation. New York University, New York, p. 232

Gu XF, Azmitia EC (1989): Psychotropic Amphetamines Cause a Preferential Release of Non-Vesicular 5-HT. Soc Neurosci Abst 15:418

Harvey JA, McMaster SE, Fuller RW (1980): Comparison Between the Neurotoxic and Serotonin-Depleting Effects of Various Halogenated Derivatives of Amphetamine in Rat. J Pharmacol Exp Ther 202:581-589

Hekmatpanah CR, Peroutka SJ (1990): 5-Hydroxytryptamine Uptake Blockers Attenuate the 5-Hydroxytryptamine Releasing Effect of 3,4-Methylenedioxymethamphetamine and Related Agents. Eur J Pharmacol 177:95-98

Hwang EC, van WoertMH (1980): Comparative Effects of Substituted Phenethylamines in Brain Serotonergic Mechanisms. J Pharmacol Exp Ther 228:254-260

Jacocks HM III, Cox BM(1992): Serotonin-Stimulated Release of $\left[{ }^{3} \mathrm{H}\right]$-Dopamine via Reversal of the Dopamine Transporter in Rat Striatum and Nucleus Accumbens: A Comparison with Release Elicited by Potassium, N-MethylD-Aspartic Acid, Glutamic Acid and D-Amphetamine. J Pharmacol Exper Ther 262:356-364

Johnson MP, Hoffman AJ, Nichols DE (1986): Effects of the Enantiomers of MDA, MDMA and Related Analogues on $\left[{ }^{3} \mathrm{H}\right]$-Dopamine Release from Superfused Rat Brain Slices. Eur J Pharmacol 132:269-276

Johnston JP (1968): Some Observations Upon a New Inhibitor of Monoamine Oxidase in Rat Brain Tissue. Biochem Pharmacol 17:1285-1297

Kannengiesser M-H, Hunt PF, Raynaud J-P (1976): Comparative Action of Fenfluramine on the Uptake and Release of Serotonin and Dopamine. Eur J Pharmacol 35:35-43

Lan NC, Chen C, Shih JC (1989): Expression of Functional Human Monoamine Oxidase A and B cDNAs in Mammalian Ceills. J Neurochem 52:1652-1654

Levitt P, Pintar JE, Breakefield XO (1982): Immunocytochem- 
ical Demonstration of Monoamine Oxidase B in Brain Astrocytes and Serotonergic Neurons. Proc Natl Acad Sci USA 115:1617-1624

Lowry O, Rosebrough N, Farr A, Randall R (1951): Protein Measurement with the Folin Phenol Reagent. J Biol Chem 193:265-275

Mamounas LA, Molliver ME (1988): Evidence for Dual Serotonergic Projections to Neocortex: Axons from the Dorsal and Median Raphe are Differentially Vulnerable to the Neurotoxin p-Chloroamphetamine (PCA). Exp Neurol 102:23-26

Mantle TJ, Tipton KF, Garret NJ (1976): Inhibition of Monoamine Oxidase by Amphetamine and Related Compounds. Biochem Pharmacol 25:2073-2077

Miller HH, Shore PA, Clarke DE (1980): In Vivo Monoamine Oxidase Inhibition by Amphetamine. Biochem Pharmacol 29:1347-1354

Molliver DC, Molliver ME (1990): Anatomic Evidence for a Neurotoxic Effect of $( \pm)$ Fenfluramine Upon Serotonergic Projections in the Rat. Brain Res 511:165-168

O'Hearn E, Battaglia G, DeSouza EB, Kuhar MJ, Molliver ME (1988): Methylenedioxyamphetamine (MDA) and Methylenedioxymethamphetamine (MDMA) Cause Selective Ablation of Serotonergic Axon Terminals in Forebrain: Immunocytochemical Evidence for Neurotoxicity. J Neurosci 8 (8): 2788-2803

Patterson MK Jr, Maxwell MD (1973): Preparation of Sera for Nutritional Studies. In Tissue Culture: Methods and Applications, Kruse PF, Patterson MK Jr (eds), New York: Academic Press, pp. 682-686

Pearce LB, Roth JA (1985): Human Brain Monoamine Oxidase Type B: Mechanism of Deamination as Probed by Steady State Methods. Biochem 24:1821-1826

Pintar JE, Barbosa J, Francke U, Castiglione M, Hawkins M, Breakefield XO (1981): Gene for Monoamine Oxidase Type A Assigned to the Human X Chromosome. J Neurosci $1: 166-175$
Poblete JC, Whitaker-Azmitia PM, Azmitia EC (1989): The Effects of Drugs of Abuse and Selected Serotonin Agonists on the High-Affınity Serotonin Transporter; Displacement of $\left[{ }^{3} \mathrm{H}\right]$-Paroxetine. Soc Neurosci Abstr 15 (1): 418

Ross SB, Froden O (1977): On the Mechanism of the Acute Decrease of Rat Brain Tryptophan Hydroxylase Activity by 4-Chloroamphetamine. Neurosci Let 5:215-220

Ross SB, Ogren SV, Renyi AL (1977): Substituted Amphetamine Derivatives. I. Effect on Uptake and Release of Biogenic Amines and on Monoamine Oxidase in Mouse Brain. Acta Pharmacol et Toxicol 41:337-352

Schmidt CJ (1987): Neurotoxicity of the Psychedelic Amphetamine, Methylenedioxyamphetamine. J Pharmacol Exp Ther 240:1-7

Schmidt CJ, Levin JA, Lovenberg W (1987): In Vitro and In Vivo Neurochemical Effects of Methylenedioxyamphetamine on Striatal Monoaminergic Systems in the Rat Brain. Biochem Pharmacol 36:747-755

Sotelo C, Zamora A (1978): Lack of Morphological Changes in the Neurons of the B9 Group of Rats Treated with Fenfluramine. Curr Med Res Opin 6:55-62

Steele TJ, Nichols DE, Yim GKW (1987): Stereochemical Effects of 3,4-Methylenedioxymethamphetamine (MDMA) and Related Amphetamine Derivatives on In-

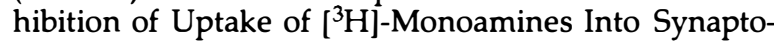
somes from Different Regions of Rat Brain. Biochem Pharmacol 36:2297-2303

Stone DM, Stahl DC, Hanson GR, Gibb JW (1986): The Effects of 3,4-Methylenedioxymethamphetamine (MDMA) and 3,4-Methylenedioxyamphetamine (MDA) on Monoaminergic Systems in the Rat Brain. Eur J Pharmacol 128:41-48

Westlund KN, Denney RM, Kochersperger LM, Rose RM, Abell AW (1985): Distinct Monoamine Oxidase-A and -B Populations in Primate Brain. Science 230:181-183

Yang H-Y, Neff NJ (1974): The Monoamine Oxidases of Brain: Selective Inhibition with Drugs and the Consequences for the Metabolism of the Biogenic Amines. J Pharmacol Exp Ther 189:733-740 